\section{Procesos de territorialización en torno a la gestión de un humedal y sus consecuencias. El caso del sudeste de los Esteros del lberá, provincia de Corrientes (1983-2018)}

Tesis de Doctorado en Geografía

\author{
Autora: Esp. María Abelina Acosta Felquer ${ }^{1}$ \\ Pertenencia institucional actual: Universidad \\ Nacional de La Matanza \\ Pertenencia institucional de Tesis: Universidad \\ Nacional de Buenos Aires \\ @ [ abelina.acosta@yahoo.com.ar ] \\ Directora: Dra. María Carolina Feito \\ Co-director: Dr. Andrés Barsky
}

Defensa Pública de Tesis: septiembre de 2019

DOI: http://dx.doi.org/10.19137/huellas-2020-2426

$\mathrm{E}^{1}$ interés por abordar esta temática responde a la escasez de estudios detallados sobre los procesos de territorialización que se han suscitado desde 1983 hasta el año 2018 en los Esteros del Iberá, en virtud de los nuevos actores que han entrado en juego. La información que circula mayoritariamente en ámbitos académicos y públicos está vinculada con la divulgación de estudios científicos que analizan las características naturales del ecosistema de humedal o de su promoción como destino turístico o de algunas características culturales de los pobladores, sin tener en consideración la cotidianeidad conflictiva en la que está inserta la población local. Por ello, y sumado a nuestra

1 Becaria Postdoctoral de CONICET (2019-2021). Docente titular de la UCP (2017 y 2019). Docente de enseñanza media. Investigadora y colaboradora en proyectos de investigación en la UNLP y UNLAM. Esta tesis se realizó en el marco de un proyecto mayor de investigación denominado "Los Esteros del Iberá y humedales adyacentes: un abordaje desde los conflictos ambientales y los actores sociales" (UNLP). experiencia en el área, la originalidad de esta investigación radica en considerar territorializaciones desde dos dimensiones: la de las políticas públicas que le dieron nuevo estatus territorial a los esteros y la del rol de las organizaciones sociales e instituciones locales.

El objeto de estudio de esta investigación es analizar cómo fueron desarrollándose los distintos procesos de territorialización en la región sudeste de los Esteros del Iberá, motorizados por la expansión de los sectores arrocero y turístico, en el marco de la creciente apertura económica registrada en los últimos treinta y cinco años. Así como las acciones de intervención realizadas por organizaciones ambientalistas, el Estado provincial y el Estado nacional en torno al humedal, crecientemente puesto en valor como recurso natural y económico. También se busca indagar cómo el desembarco de todos esos nuevos actores afectó al entramado social local (generación de cambios de hábitos, de empleos, de migraciones) en Colonia Carlos Pellegrini, con énfasis en el rol que han jugado en dichas transformaciones las organizaciones públicas y privadas con actuación en la región.

En esta tesis, se tiene en cuenta al macrosistema Iberá como contexto pero el análisis se focaliza en la región sudeste con énfasis en la localidad Colonia Carlos Pellegrini (en adelante, CCP), localizada en el departamento San Martín de la provincia de Corrientes. La investigación empírica se centra allí dada su estratégica ubicación que ha permitido el acceso directo al humedal y que por ello desde 1983 se han desarrollado distintas actividades relacionadas al turismo, convirtiéndose en un lugar atractivo para nuevos actores y organizaciones que impactaron en las relaciones sociales preexistentes.

En el campo metodológico se utiliza el enfoque etnográfico, que permite indagar en las perspectivas de los miembros 


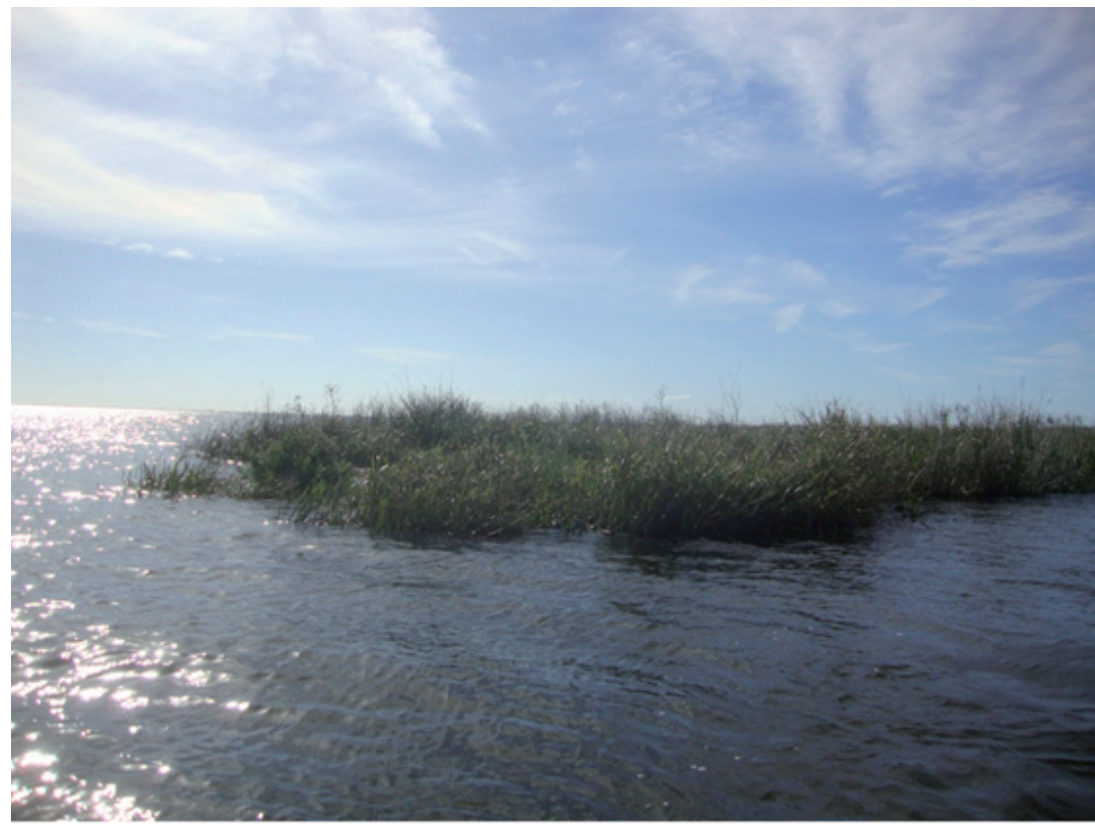

Fuente: archivo propio.

de la comunidad de CCP y el sentido que le otorgan a sus prácticas. Como vías de acceso a lo real se considera la observación y la participación, que son dos vías específicas y complementarias, ya que la mera observación requiere un grado mínimo de participación para obtener información significativa (Guber, 2001). Por otra parte, utilizamos la entrevista no directiva como la técnica más apropiada para acceder al universo de significación de los actores. En definitiva, en esta tesis se utiliza una metodología propia de la disciplina antropológica en un estudio de carácter geográfico.

Como resultados de esta investigación, en primer lugar, se evidencia que los datos demográficos de la macrorregión Iberá variaron como consecuencia de los nuevos emprendimientos económicos. Por un lado, las actividades tradicionales (ganadería y agricultura) registraron cambios, ya que pasaron a ser controladas por grandes y medianos productores. Por otro, la creación de la reserva natural ha causado procesos de desplazamiento de actividades preexistentes, como la caza y la pesca de subsistencia, aunque ciertos saberes previos se conservaron (Porto-Gonçalvez, 2015) dado el paso de antiguos mariscadores a guardaparques. Por último, el auge del ecoturismo ha puesto en valor la producción artesanal local.

A partir del recorrido histórico de las políticas implementadas se visibiliza la lenta intervención de organismos internacionales y ONGs interesados en la protección exclusivamente natural de los Esteros del Iberá. Este tipo de conservación provocó la pérdida del modo de vida tradicional de los pobladores que, desde esta perspectiva, muchas veces fue considerado peligroso e, incluso, ilegal. 
Distintas políticas públicas han buscado la protección de la enorme biodiversidad de los esteros. En principio, se puede mencionar la creación de la Reserva Provincial Iberá en 1983 por Ley Provincial $\mathrm{N}^{\mathrm{o}} 3.771 / 83$, de 1.300 .000 hectáreas de superficie que coinciden con la cuenca alta del río Corriente y con toda la cuenca iberana. Luego, en enero de 2002, por Ley $\mathrm{N}^{\circ}$ 23.919 se convirtieron 24.550 hectáreas en Sitio Ramsar. En el año 2009, mediante el Decreto $\mathrm{N}^{\mathrm{o}} 1.440 / 09$, se creó al interior de la Reserva Provincial el Parque Provincial Iberá - de conservación estricta-, que coinciden con las tierras de dominio público. En el año 2016 las 482.000 hectáreas conservadas pasaron a ser 550.000. Desde entonces se elabora el Plan Maestro para el Desarrollo del Iberá e intenta formalizar la creación del Parque Nacional Iberá. Al momento de escribirse el presente trabajo de tesis, el proyecto de ley tratado en el Senado Nacional obtuvo media sanción el 18 de abril del 2018 y aún restaba la sanción de la Cámara de Diputados.

Estas distintas formas de intervención (el Sitio Ramsar, la Reserva Provincial, el Parque Provincial, el futuro Parque Nacional, el Plan Maestro) expresan la forma en que el Estado ha concebido una determinada forma de intervención. Además, la superposición de áreas de conservación evidencia una serie de intereses puestos en juego que serán analizados a lo largo de esta investigación. Un actor social que ha tenido gran influencia en la conservación ambiental y el crecimiento del turismo es una organización internacional denominada Conservation Land Trust (CLT).

Las prioridades de la gestión nacional actual sobre el territorio de los Esteros privilegian al turismo como una importante actividad económica en el medio rural, respaldada por los organismos internacionales de financiamiento ("autora" y Pohl Schnake, 2017).
Las políticas públicas han sido impuestas, con excepción de la Agencia de Extensión Rural INTA Mercedes que mostró la intención incluir a la población rural en las decisiones de algunas actividades y con las propuestas recientes de la actual viceintendencia de CCP.

Fenómenos como la extranjerización de tierras, la evolución de las empresas arroceras, los emprendimientos turísticos $\mathrm{y}$ forestales que protagonizan nuevos procesos de territorialización y conflictos en el macrosistema Iberá. Con ello se busca visibilizar las tensiones generadas entre los distintos actores. Los procesos descriptos demuestran que los Esteros del Iberá constituyen un territorio en construcción, en movimiento, en permanente cambio (Haesbaert, 2013; Porto Gonçalves, 2015), ya que los intentos de apropiación del mismo para obtener poder sobre el territorio, se han traducido en procesos de reterritorialización que han ocasionado conflictos que plantean nuevas aristas (Porto Gonçalvez, 2015). Existen grupos de población que buscan resguardar sus prácticas tradicionales e identidades y sienten que su realidad fue apropiada bajo el discurso tradicional del conservacionismo. Por este motivo, Iberá Patrimonio de los Correntinos (ONG local), pobladores rurales y otros actores sociales dejan entrever el poder implícito de la CLT y lo llevan al campo de las políticas públicas mediante distintas manifestaciones.

En la región sudeste de los Esteros del Iberá el impacto del turismo ha quedado de manifiesto al desplazar a la producción agrícola, a la caza y a la pesca, mientras que la ganadería extensiva se ha extendido, es decir, ha ganado territorio. La pequeña producción de arroz ha sido reemplazada por grandes arroceras tecnificadas. Y mientras que la ganadería vacuna de medianos y grandes productores ganaderos se ha consolidado, la caza y la pesca de subsistencia han desaparecido. 
A escala local, en CCP, estos cambios han atraído nuevos actores que se hibridaron con la cultura local (Haesbaert, 2013), afectándola, como ocurrió en el caso de muchos jóvenes y adultos pellegrineros. Por otro lado, algunos adultos perciben cambios en su modo de socialización por el proceso de la mezcla cultural. De esta manera, advertimos cómo el turismo (particularmente internacional) condujo a importantes transformaciones en los sistemas de representación y en las formas culturales de la sociedad local (Harvey, 1998). Estos cambios en la representación de la identidad intergeneracional, se relacionan con la interpretación de nuevos códigos culturales que traen los turistas y los dueños de emprendimientos turísticos extralocales. En este sentido, podemos hablar de una reterritorialización en el plano simbólico.

Como conclusiones, el papel que el gobierno municipal cumple es el de promover la actividad turística como la única de importancia, lo cual podría prolongar la existencia de conflictos como los descriptos, al dirigir el accionar de la gestión a un solo y único objetivo.

Los procesos de territorialización producidos en los Esteros del Iberá fueron consecuencia de la extranjerización, la creación de áreas de protección natural, la instalación de emprendimientos turísticos y la producción arrocera a gran escala. Estos mismos procesos de territorialización produjeron tensiones y conflictos. También modificaron la economía y la cultura de las poblaciones tradicionales.

Las iniciativas políticas de los distintos niveles del Estado presentan escasa consistencia. Por ejemplo, el Estado Nacional promueve actividades participativas para rescatar la cultura local, a través de la actuación de la agencia del INTA Mercedes, a la vez que permite la libre acción de una ONG internacional como CLT, que valora la conservación ambiental en términos estrictos por sobre los modos de vida de la población local. Asimismo, el gobierno provincial facilita el desarrollo de poderosos actores económicos en la región que vulneran la producción de los pequeños productores pero, por otro lado, a través del proyecto del Plan Maestro busca promover el desarrollo de la comunidad.

\section{Referencias bibliográficas}

Acosta Felquer y Pohl Schnake, V. (2017). ¿Qué sucede en los Esteros del Iberá? Tendencias territoriales y manejo de los bienes comunes. En L. Ramírez (Presidencia), Consolidando la Geografia en Red. Conferencia llevada a cabo en el VI Congreso Nacional de Geografía de Universidades Públicas, Chaco, Argentina.

Guber, R. (2001). La etnografia. Método, campo y reflexividad. Bogotá, Colombia: Grupo Editorial Norma.

Haesbaert, R. (2013). Del mito de la desterritorialización a la multiterritorialidad. Cultura y representaciones sociales, volumen 8 (15), pp. 9-41.

Harvey, D. (1998). La condición de la posmodernidad. Investigación sobre los orígenes del cambio cultural. Buenos Aires, Argentina: Amorrortu.

Porto-Gonçalvez, C.W. (2015). Geo-grafías. Cardinalis, volumen 3 (4), pp. 230-263. 